\title{
Two prostate cancer-associated polymorphisms in the 3 'UTR of IGF1R influences prostate cancer susceptibility by affecting miRNA binding
}

\author{
HUIMIN WANG ${ }^{1 *}$, WENTAO HUANG ${ }^{2 *}$, XIAOXIANG YU ${ }^{3 *}$, WEIDONG LI ${ }^{1}$, YUANJIE HUANG ${ }^{1}$, \\ ZENGNAN MO ${ }^{4}$, YONG GAO ${ }^{4,5}$, QINGNIAO ZHOU ${ }^{6,7}$ and YANLING $\mathrm{HU}^{1,4,6}$ \\ ${ }^{1}$ Life Sciences Institute; ${ }^{2}$ Pharmaceutical College, Guangxi Medical University; ${ }^{3}$ Department of Urology, \\ The 303rd Hospital of Chinese People's Liberation Army; ${ }^{4}$ Center for Genomic and Personalized Medicine, \\ Guangxi Medical University; ${ }^{5}$ Department of Clinical Laboratory, The First Affiliated Hospital of Guangxi \\ Medical University; ${ }^{6}$ Guangxi Colleges and Universities Key Laboratory of Biological Molecular Medicine Research; \\ ${ }^{7}$ Department of Biochemistry and Molecular Biology, School of Pre-Clinical Medicine, \\ Guangxi Medical University, Nanning, Guangxi 530021, P.R. China
}

Received February 27, 2018; Accepted September 19, 2018

DOI: $10.3892 / o r .2018 .6810$

\begin{abstract}
Prostate cancer (PCa) is a common malignant cancer in men worldwide. Numerous genetic variations have been associated with PCa, but their biological function remains unclear. Single nucleotide polymorphisms (SNPs) inside $3^{\prime}$ untranslated region (UTR) affect gene expression, with one essential mechanism being regulation by micro (mi)RNAs. Based on data from genome-wide association study of the Consortium for Chinese Consortium for Prostate Cancer Genetics, rs1815009 and rs2684788 inside 3'UTR of insulin-like growth factor 1 receptor (IGF1R) presented significant genotype distribution between PCa and control samples. In the current study, targeting miRNAs were predicted using TargetScan and miRanda. The prediction was confirmed using a thermodynamic model for miRNA-target interaction and luciferase reporter assays for miRNA binding inside IGF1R 3'UTR. Furthermore, data from public databases and miRNA overexpression further supported miRNAs function. The results suggested that miR-133a and miR-133b may bind near rs1815009, and miR-455 near rs2684788, within IGF1R
\end{abstract}

Correspondence to: Professor Yanling Hu, Center for Genomic and Personalized Medicine, Guangxi Medical University, 22 Shuangyong Road, Nanning, Guangxi 530021, P.R. China

E-mail: ylhupost@163.com

Dr Qingniao Zhou, Department of Biochemistry and Molecular Biology, School of Pre-Clinical Medicine, Guangxi Medical University, 22 Shuangyong Road, Nanning, Guangxi 530021, P.R. China

E-mail: ebirdie123@126.com

*Contributed equally

Key words: prostate cancer, polymorphisms, 3' translated region, microRNA, insulin-like growth factor 1 receptor
3'UTR. Compared with normal tissues, miR-133a, miR-133b and miR-455 exhibited significantly lower expression in $\mathrm{PCa}$ tissues in the public datasets analyzed. The results of the present study revealed an association between rs1815009, rs2684788 and PCa risk, which involves altered miRNA regulation and contributes to cancer susceptibility.

\section{Introduction}

Prostate cancer ( $\mathrm{PCa})$ is the second most frequently diagnosed cancer in men worldwide (1), and remains a leading cause of cancer-associated mortality (2). The incidence rates for PCa increased between 2000 and 2011, with an estimated 60,300 new cases in China in 2015 (3). Genetic variations affect the initiation and progression of $\mathrm{PCa}$, and men with a family history of PCa have a two-fold increased risk of developing $\mathrm{PCa}$, usually with an earlier age of onset (4). Genome-wide association studies (GWAS) have identified 100 risk variants for PCa, which may explain $\sim 33 \%$ of the familial risk of the disease (5). However, the biological function of numerous genetic variations remains to be discovered.

Accumulating evidence suggests gene expression may be altered by single nucleotide polymorphisms (SNPs) in the 3' untranslated region (UTR), and one essential mechanism involves regulation by microRNAs (miRNAs) $(6,7)$. miRNAs are small non-coding RNAs, composed of 18-24 nucleotides, that are involved in the regulation of essential biological processes, including cell proliferation, differentiation and apoptosis $(8,9)$. miRNAs modulate the expression of protein-coding genes by binding to the full or part of their complementary sequence in the $3^{\prime}$ or 5'UTR of the coding sequence $(10,11)$. Polymorphisms in miRNA binding sites affect the binding efficacy of miRNAs and consequently alter the expression of target genes $(6,7,9,12,13)$.

Insulin-like growth factor 1 receptor (IGF1R) is a transmembrane tyrosine kinase receptor, characterized by a heterodimer of $\alpha$ - and $\beta$-chains, and is activated by its ligands 
insulin-like growth factor 1 (IGF1) and insulin-like growth factor 2 (IGF2) (14). Activation of IGF1R is associated with improved growth, proliferation, angiogenesis and survival (15). Numerous studies have demonstrated that IGF1R serves an important role in the risk and progression of PCa $(16,17)$. In our previous study (18), an association analysis for the reverse tyrosine kinase-extracellular signal-regulated kinase pathway was performed based on the GWAS data from the Consortium for Chinese Prostate Cancer Genetics (ChinaPCa), which identified two SNPs (rs1815009 and rs2684788) in the 3'UTR of IGF1R presented significant genotype distribution between $\mathrm{PCa}$ and control samples.

Based on the important regulatory function of miRNAs at the transcriptional level, two miRNA binding prediction tools [TargetScan (19) and miRanda (20)] were used to predict the binding of miRNAs in the IGF1R 3'UTR. The predicted results revealed that miR-133a and $\mathrm{miR}-133 \mathrm{~b}$ may bind near rs1815009, and miR-455 near rs2684788, within the IGF1R 3'UTR. In addition, a thermodynamic model was applied to analyze the binding affinity of miR-133a and miR-133b for rs1815009, and miR-455 for rs2684788 under different variants, which demonstrated that the binding of these miRNAs would be affected. A dual-luciferase reporter assay was performed on 293 cells to verify the binding affinity predicted by the thermodynamic model. Finally, whether IGF1R expression was affected by these miRNAs was investigated through overexpression of miR-133a, miR-133b or mir-455 in PC3 and LNCaP cells.

\section{Materials and methods}

Thermodynamic model for the miRNA-target interaction. The sequence of the 3'UTR of IGF1R was retrieved from the University of California Santa Cruz database (http://genome. ucsc.edu/) in the human genome assembly GRCh37/hg19. The targets for miRNA binding in the IGF1R 3'UTR containing two polymorphisms, rs1815009 or rs2684788, were predicted using the TargetScan7.1 (http://www.targetscan.org) (19) and miRanda databases (http://www.microrna.org) (20). Mature human sequences were downloaded from the National Center for Biotechnology Information (https://www.ncbi.nlm.nih.gov/). A parameter-free thermodynamic model was used $(21,22)$ to investigate the binding affinity of miR-133a and miR-133b for the $\mathrm{C}$ or $\mathrm{T}$ allele of rs1815009, and miR-455 for the $\mathrm{C}$ or $\mathrm{T}$ allele ofrs2684788. In this model, $\mathrm{E}_{\text {Target }}$ represented the energy of the dissociated mRNA target region with no miRNAs interacting with it, $\mathrm{E}_{\text {Intermediate }}$ indicated the energy required to make the target region accessible for microRNA binding, and $\mathrm{E}_{\text {Complex }}$ is the energy of the microRNA-target complex, the binding of which was consistent with the constraints imposed by the seed region $(6,7,23)$. RNAfold software (Vienna RNA Package; http://rna.tbi.univie.ac.at/cgi-bin/RNAWebSuite/RNAfold.cgi) was used to compute all ensemble free energies with the partition function algorithm for folding and the default settings. The RNAfold was modified to calculate the $\mathrm{E}_{\text {Intermediate }}$ and $\mathrm{E}_{\text {Complex }}$ in order to construct the connectivity matrix of the intermediate or complex product secondary structures, and the corresponding structure-associated energies were calculated. The target sequence size contained the relevant miRNA target seed region, the relevant IGF1R SNP site and the nucleotides surrounding the SNP site. The site length provided for the RNAfold was $42 \mathrm{nt}$ for rs1815009 and $60 \mathrm{nt}$ for rs2684788. The value of the selected target size for rs1815009 and rs2684788 was chosen to reduce the time complexity of the aforementioned computations, particularly as the results were not altered when the length of the target was extended (Fig. 1). The $\Delta \mathrm{E}_{\mathrm{a}}$ is the difference between $\mathrm{E}_{\text {Target }}$ and $\mathrm{E}_{\text {Intermediate }}$, and $\Delta \mathrm{E}_{\mathrm{b}}$ is the difference between $\mathrm{E}_{\text {Target }}$ and $\mathrm{E}_{\text {Complex }}(6,7)$.

Literature search. A thorough literature search was performed using PubMed on miRNA expression profiling studies for $\mathrm{PCa}$ with the following key words: Prostate and (cancer OR tumor OR tumor) and (mirna OR microrna OR mir-). Additionally, miRNA expression profiles for $\mathrm{PCa}$ were retrieved by searching the Gene Expression Omnibus (GEO) (http://www. ncbi.nlm.nih.gov/geo/) (24). Profiles whose data published between June 14, 2007 and April 28, 2015 were selected. The inclusion criteria were as follows: i) Experimental samples consisting of prostate tumor and non-tumor tissues, for which the complete raw or normalized microarray data was available; ii) data included genome-wide miRNA expression; iii) Homo sapiens as the studied organism; iv) samples that had not been subjected to adjuvant therapy; and v) the number of PCa and normal controls was $>15$. For the present study, the non-tumor tissues included adjacent tissues of PCa or tissues from independent healthy donors, but excluded benign prostatic hyperplasia. The data extracted from each GEO dataset was as follows: Tumor sample type, country, platform, experimental materials and number of samples (Table I). The list of miRNAs with statistically significant expression in PCa was extracted from the publications. All statistical analyses were performed using GEO2R.

Processing of data obtained from the cancer genome atlas. The normalized miRNA-HiSeq expression values and $\mathrm{PCa}$ clinical information was downloaded from the Cancer Genome Atlas (TCGA) (http://cancergenome.nih.gov/). The reads/million miRNA mapped (RPM) normalized values for miRNA expression were further $\log _{2}$-transformed. The fold change in miRNA expression between tumors and normal tissues was calculated using the median-centered RPM values. The information for TCGA dataset is presented in Table I. The difference in expression between PCa and normal tissue was analyzed using an independent sample t-test.

Plasmid construction and luciferase reporter assay. Truncated UTR sequences containing the SNP region were amplified by polymerase chain reaction (PCR) from genomic DNA, then ScaI cloned into the 3'UTR of the pmirGLO-control vector (Promega Corporation, Madison, WI, USA) following the manufacturer's protocol. The 3'UTR reporter vector for IGF1R, containing the $\mathrm{C}$ allele of rs1815009 and seed region of miR-133a or miR-133b, was named pmirGLO-rs1815009-IGF1R-[C]. Plasmids carrying the 3'UTR with the T allele were designated as pmirGLO-rs1815009-IGF1R-[T]. Likewise, two 3'UTR constructs for rs2684788 containing the $\mathrm{C}$ or $\mathrm{T}$ alleles were designated as pmirGLO-rs2684788-IGF1R-[C] and pmirGLO-rs2684788-IGF1R-[T]. Each plasmid was co-transfected with the miRNA precursor (pre-133a, pre-133b, 
Table I. Brief overview of the GEO datasets.

\begin{tabular}{|c|c|c|c|c|c|}
\hline Series ID & $\begin{array}{l}\text { Tumor } \\
\text { sample type }\end{array}$ & Country & Platform & $\begin{array}{l}\text { Experimental } \\
\text { materials }\end{array}$ & $\begin{array}{c}\text { Number of } \\
\text { samples }\end{array}$ \\
\hline GSE36803 & Primary & North American & Affymetrix GeneChip array & Tissue (Homo sapiens) & 21 pairs \\
\hline GSE8126 & Primary & North American & $\begin{array}{l}\text { OSU-CCC hsa-miRNA-chip } \\
\text { version } 3\end{array}$ & Tissue (Homo sapiens) & $60 \mathrm{~T}+16 \mathrm{~N}$ \\
\hline TCGA & Primary & North American & Illumina HiSeq 2000 miRNASeq & Tissue (Homo sapiens) & $498 \mathrm{~T}+52 \mathrm{~N}$ \\
\hline
\end{tabular}

T, tumor sample; N, non-tumor sample; TCGA, The Cancer Genome Atlas; GEO, Gene expression omnibus.

pre-455 or scrambled negative control; Shanghai GenePharma Co., Ltd., Shanghai, China) in 293 cells cultured in 24-well plates. The following sequences were used: Pre-133a, AAT TCACAATGCTTTGCTAGAGCTGGTAAAATGGAACCA AATCGCCTCTTCAATGGATTTGGTCCCCTTCAACCA GCTGTAGCTATGCATTGAACCGG; pre-133b, AATTCC CTCAGAAGAAAGATGCCCCCTGCTCTGGCTGGTCAA ACGGAACCAAGTCCGTCTTCCTGAGAGGTTTGGTCC CCTTCAACCAGCTACAGCAGGGCTGGCAATGCCCAG TCCTTGGAGAACCGG; pre-455, AATTCTCCCTGGCGT GAGGGTATGTGCCTTTGGACTACATCGTGGAAGCCA GCACCATGCAGTCCATGGGCATATACACTTGCCTCA AGGCCTATGTCATCACCGG; and scrambled negative control, AAATGTACTGCGCGTGGAGAC. Following transfection with Lipofectamine 2000 reagent (Invitrogen; Thermo Fisher Scientific, Inc., Waltham, MA, USA), $1.5 \times 10^{6}$ cells $/ \mathrm{ml}$ cells were cultured for $24 \mathrm{~h}$, then lysed in passive lysis buffer, according to the Dual-Luciferase ${ }^{\circledR}$ Reporter Assay system kit (Promega Corporation), and luciferase activity was measured with a Tecan M1000 microplate reader (Tecan Group, Ltd., Mannedorf, Switzerland). A dual-luciferase system was utilized in this assay, containing two luciferase enzymes, one containing the $\operatorname{luc}_{2}$ reporter gene that reports miRNA activity, and another containing the hRluc-neo reporter gene used as a control reporter for normalization of gene expression. Normalization of the empty pmirGLO vector was performed using the Renilla/firefly luciferase ratios. Each luciferase assay was performed in triplicate and the mean value was calculated.

Cell culture and transfection. The human $\mathrm{PCa}$ cell line PC3 was obtained from the American Type Culture Collection (Manassas, VA, USA), and the human PCa cell line LNCaP and the 293 cell line were purchased from the Type Culture Collection of the Chinese Academy of Sciences (Shanghai, China). The PC3 cells were maintained in Dulbecco's modified Eagle's medium (DMEM)/F12 (HyClone; GE Healthcare Life Sciences, Logan, UT, USA) supplemented with $10 \%$ (v/v) fetal bovine serum (FBS; Gibco; Thermo Fisher Scientific, Inc.). LNCaP cells were cultured in RPMI-1640 (Gibco; Thermo Fisher Scientific, Inc.) with $10 \%$ (v/v) FBS, and 293 was cultured in DMEM supplemented with $10 \%$ (v/v) FBS, $1 \%$ (v/v) penicillin and streptomycin. All cultures were cultured in an incubator set to $37^{\circ} \mathrm{C}$ with $5 \% \mathrm{CO}_{2}$. Then, $0.5 \mu \mathrm{g}$ knockdown synthetic oligonucleotides (pre-133a, pre-133b, pre-455, pre-455 inhibitor and pre-control) were transfected when cells reached $80-90 \%$ confluence, using Lipofectamine 3000 reagent (Invitrogen; Thermo Fisher Scientific, Inc.), according to the manufacturer's protocol.

DNA sequencing. PC3 and LNCaP cells at the log growth phase were collected for DNA isolation. Genomic DNA was extracted using MiniBEST Universal Genomic DNA Extraction kit (Takara Bio, Inc., Otsu, Japan), following the manufacturer's protocol. The SNP-containing region was amplified with Premix Taq (Takara Bio, Inc.). Sequencing of the PCR product was performed using the BigDye Terminator Reaction Chemistry v3.1 sequencing kit (Thermo Fisher Scientific, Inc.) according to the manufacturer's protocol, and sequence analyses were performed with DNASTAR 7.0 (DNASTAR, Madison, WI, USA).

RNA extraction and reverse transcription-quantitative polymerase chain reaction $(R T-q P C R)$. After $48 \mathrm{~h}$ of transfection, the PC3 and LNCaP cells were harvested for RNA isolation. Total RNA was extracted using the mirVana ${ }^{\mathrm{TM}}$ miRNA Isolation kit (Ambion; Thermo Fisher Scientific, Inc.), following the manufacturer's protocol. Total RNA from PC3 and LNCaP cells was used to synthesize cDNA using the PrimeScript $^{\mathrm{TM}}$ RT Master Mix (Takara Bio, Inc.). The PCR reaction conditions were as follows: $37^{\circ} \mathrm{C}$ for $15 \mathrm{~min}$ and $85^{\circ} \mathrm{C}$ for $5 \mathrm{sec}$. RT-qPCR was performed in triplicate using PowerUp ${ }^{\mathrm{TM}}$ SYBR ${ }^{\circledR}-$ Green Master mix with a 7500 Real-Time PCR System (both form Applied Biosystems; Thermo Fisher Scientific, Inc.). The RT-qPCR reaction conditions were as follows: $50^{\circ} \mathrm{C}$ for $5 \mathrm{~min} ; 95^{\circ} \mathrm{C}$ for $2 \mathrm{~min}$; and 40 cycles of $95^{\circ} \mathrm{C}$ for $15 \mathrm{sec}$ and $60^{\circ} \mathrm{C}$ for $1 \mathrm{~min}$. The primers used are listed in Table II. The relative mRNA expression in the control and experimental groups of PC3 and LNCaP was determined using the $2^{-\triangle \Delta \mathrm{Cq}}$ method (25), and normalized to GAPDH or $\beta$-actin mRNA expression levels.

Western blot analysis. Post-transfected cells (PC3 and $\mathrm{LNCaP}$ ) were collected for protein isolation following $48 \mathrm{~h}$ of incubation. Total protein was extracted with radioimmunoprecipitation assay buffer (Beyotime Institute of Biotechnology, Beijing, China) with Halt Protease Inhibitor Cocktail (100X; Thermo fisher Scientific, Inc.) and quantified with the bicinchoninic acid assay, and $50 \mu \mathrm{g}$ of protein/lane was separated on a $12 \%$ SDS-PAGE gel and transferred to a $0.2-\mu \mathrm{m}$ 
Table II. Primer sequences used in the present study.

\begin{tabular}{|c|c|}
\hline Genes & Primers $\left(5^{\prime}-3^{\prime}\right)$ \\
\hline \multicolumn{2}{|l|}{ IGF1R } \\
\hline $\mathrm{F}$ & ATGCTGACCTCTGTTACCTCT \\
\hline $\mathrm{R}$ & GGCTTATTCCCCACAATGTAGTT \\
\hline \multicolumn{2}{|l|}{$\beta$-actin } \\
\hline $\mathrm{F}$ & AACTCCATCATGAAGTGTGA \\
\hline $\mathrm{R}$ & ACTCCTGCTTGCTGATCCAC \\
\hline \multicolumn{2}{|c|}{ GAPDH } \\
\hline $\mathrm{F}$ & АTCTCTGCCCССТCTGCTGA \\
\hline $\mathrm{R}$ & GATGACCTTGCCCACAGCCT \\
\hline \multicolumn{2}{|l|}{ MMP2 } \\
\hline $\mathrm{F}$ & AACTACGATGATGACCGCAAG \\
\hline $\mathrm{R}$ & GACAGACGGAAGTTCTTGGTG \\
\hline \multicolumn{2}{|l|}{ CDH1 } \\
\hline $\mathrm{F}$ & ACTCGTAACGACGTTGCACCA \\
\hline $\mathrm{R}$ & GGTCAGTATCAGCCGCTTTCAG \\
\hline \multicolumn{2}{|c|}{ VEGFA } \\
\hline $\mathrm{F}$ & СCTTGCTGCTCTACСТCCAC \\
\hline $\mathrm{R}$ & GAAGATGTCCACCAGGGTCTC \\
\hline \multicolumn{2}{|l|}{ BCL2 } \\
\hline $\mathrm{F}$ & TCGCCCTGTGGATGACTGA \\
\hline $\mathrm{R}$ & CAGAGACAGCCAGGAGAAATCA \\
\hline \multicolumn{2}{|l|}{ SNP } \\
\hline $\mathrm{F}$ & АСССАТСТСТСССАGGACC \\
\hline $\mathrm{R}$ & CTGGCAGAAGGAGGTTGCAT \\
\hline \multicolumn{2}{|l|}{ SNP2 } \\
\hline $\mathrm{F}$ & CAGGCAGCACCATCTCTGTG \\
\hline $\mathrm{R}$ & CCAATGTGCACCGAGCATCT \\
\hline
\end{tabular}

F, forward; R, reverse; IGF1R, insulin-like growth factor 1 receptor; MMP2, matrix metalloproteinase-2; CDH1, E-cadherin; VEGFA, vascular endothelial growth factor A; BCL2, B-cell lymphoma-2; SNP and SNP2, single nucleotide polymorphisms in the IGF1R3' untranslated region.

polyvinylidene fluoride membrane (EMD Millipore, Billerica, MA, USA). Blots were blocked with 5\% milk, TBS and $0.1 \%$ Tween-20 at room temperature for $2 \mathrm{~h}$. Blots were incubated with the primary anti-mouse IGF-IR antibody (cat. no., 3G5C1; 1:2,000; Novus Biologicals, Ltd., Cambridge, UK) or tubulin (cat.no., 66240-1-lg; 1:2,000; ProteinTech Group,Inc., Chicago, IL, USA) at $4^{\circ} \mathrm{C}$ for $12 \mathrm{~h}$. Subsequently, blots were incubated with the horseradish peroxidase-conjugated Affinipure Goat Anti-Mouse IgG (H+L) second antibody (cat. no., SA00001-1; 1:10,000; ProteinTech Group, Inc.) at room temperature for 2 h. BeyoECL Plus (Beyotime Institute of Biotechnology) was used as the visualization reagent. The intensity of the protein bands was quantified using Odyssey 2.1 software (LI-COR Biosciences, Lincoln, NE, USA).

Cell migration and invasion assay. Transfected LNCaP cells (pre-455, pre-455 inhibitor and pre-control) growing in the log phase were harvested for use in the migration and invasion assays. A total of $4 \times 10^{5}$ cells in serum-free RPMI-1640 (200 $\left.\mu \mathrm{l}\right)$ were seeded into the upper chamber of $8-\mu \mathrm{M}$ pore Transwell plates (Costar; Corning Incorporated; Corning, NY, USA), coated with or without Matrigel (BD Biosciences, San Jose, CA, USA). RPMI-1640 (600 $\mu \mathrm{l})$ filled with 10\% (v/v) FBS was added to the lower chamber. The cells were allowed to migrate towards RPMI-1640 containing $10 \%$ (v/v) FBS for 48 or $72 \mathrm{~h}$ at $37^{\circ} \mathrm{C}$. Cells on the top surface of the insert were removed by scraping, and the migrated and invasive cells were fixed for 10 min using $100 \%$ methanol and stained for 20 min with $1 \%$ crystal violet (both at room temperature). Subsequently, cells were imaged at x20 magnification using an inverted phase contrast microscope (TS100-F; Nikon Corporation, Tokyo, Japan), removed the crystal violet dye retained on the filters using 33\% acetic acid $(600 \mu \mathrm{l})$ and then transferred the solution containing crystal violet to 96 -well plates (150 $\mu \mathrm{l} /$ well). Values for migration and invasion were obtained by measuring absorbance of the solution at $570 \mathrm{~nm}$ using an ELISA reader (BioTek ELx-800; BioTek Instruments, Inc., Winooski, VT, USA) (26), and presented as the mean of at least three independent experiments.

Statistical data analysis. The figures were generated with GraphPad Prism 5.0 (GraphPad Software, Inc., La Jolla, CA, USA). Data are presented as the mean \pm standard error the mean and were compared using a Student's t-test (two-tailed). $\mathrm{P}<0.05$ was considered to indicate a statistically significant difference.

\section{Results}

rs1815009 $(C / T)$ overlaps the predicted binding sites of miR-133a and miR-133b, and rs2684788 (C/T) overlaps miR-455 in the IGF1R 3'UTR. The alleles of rs1815009 and rs2684788 in the IGF1R 3'UTR in the present study were primarily based on GWAS data from ChinaPCa. In our previous study, rs1815009 and rs2684788 were identified to be significantly associated with PCa using the same dataset (18). Among the PCa cases, rs1815009 was identified to be a common variant, with a frequency of $\sim 52.12 \%$ for $\mathrm{C}$ the allele and $47.88 \%$ for the $\mathrm{T}$ allele, and healthy individuals exhibited a common variant with a frequency of $\sim 48.57 \%$ for the $\mathrm{C}$ allele and $51.43 \%$ for the $\mathrm{T}$ allele. In addition, among the PCa cases, rs2684788 was demonstrated to have a frequency of $\sim 52.23 \%$ for the $\mathrm{C}$ allele and $47.77 \%$ for the $\mathrm{T}$ the allele, and the healthy population exhibited a common variant with a frequency of $\sim 47.43 \%$ for the $\mathrm{C}$ allele and $52.57 \%$ for the $\mathrm{T}$ allele. The 3'UTR was demonstrated to be an important region for miRNA binding to genes. To clarify the function of these two polymorphisms on miRNA binding, the target miRNA sequence was predicted using TargetScan and miRanda. By combining the results obtained from TargetScan (19) and miRanda (20), miR-133a, miR-133b and miR-455 were predicted to bind to the IGF1R 3'UTR (Fig. 2A). Furthermore, rs1815009 was located near the binding seed regions of miR-133a and miR-133b, and rs2684788 was located near the binding seed region of miR-455 (Fig. 2B).

Minimum free energy (MFE) of miR-133a, miR-133b and miR-455 binding to the IGFIR 3'UTR differs between allelic 
A

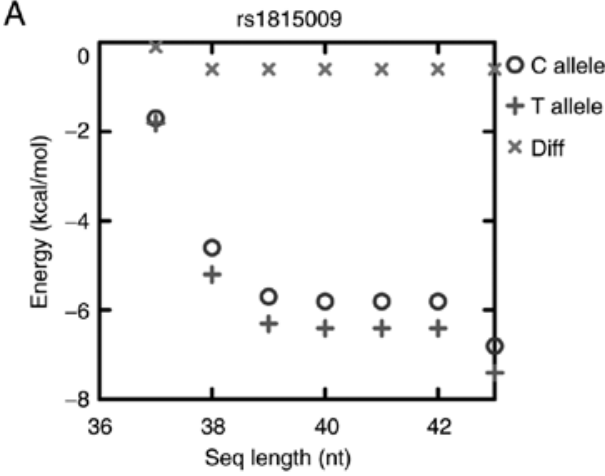

B

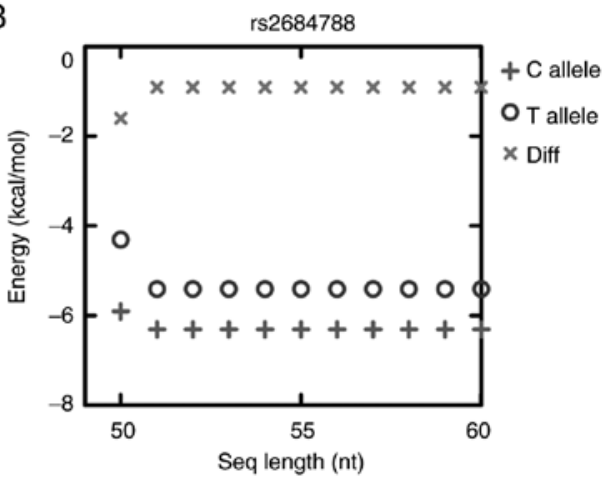

Figure 1. Energies of IGF1R 3'UTR secondary structures of different sequence lengths. MFE for the secondary structure of the IGF1R 3'UTR sequence surrounding the binding regions of (A) miR-133a or miR-133b and (B) miR-455, located $20 \mathrm{nt}$ from the relevant seed region of the 3'-end of the IGF1R 3'UTR . To avoid a sequence length-dependent effect, the free energies (y-axis) were calculated as a function of length ranging between 37 and $42 \mathrm{nt}$ extending from the 5 '-end of the miR-133a or miR-133b binding sites in an upstream direction toward the 3'UTR of IGF1R, and as a function of length ranging between 50 and $60 \mathrm{nt}$ extending from the 5'-end of the miR-455 binding site in an upstream direction. The results demonstrated that the free energies were relatively insensitive to inclusion of additional regions outside of the miRNA binding sites. Diff, energy difference between C allele and T allele structures; IGF1R, insulin-like growth factor 1 receptor; 3'UTR, 3' untranslated region; seq, sequence; MFE, minimum free energy; miR, microRNA.

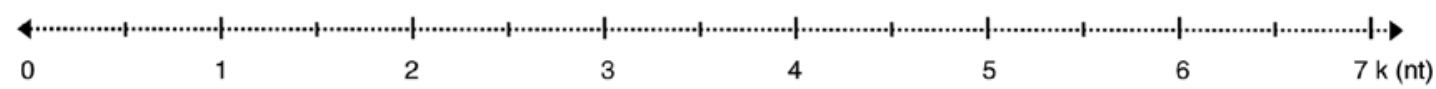

Human IGF1R NM_000875 3’ UTR (7088 nt)

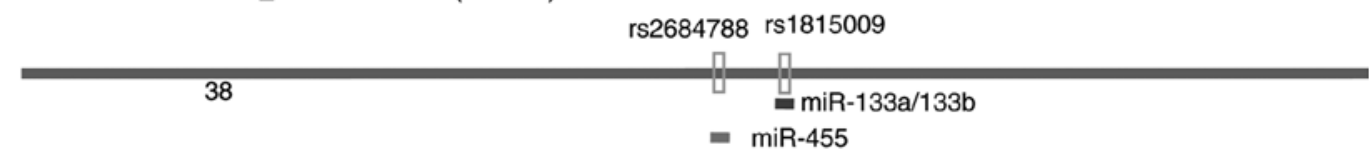

A

miR-133a (4007-4013)

IGF1R 3' UTR

$\operatorname{miR}-133 b(4007-4013)$

5' ......CAGUCA(C/U)UUUACUGGACCAACCCACCCA......3'

AUCGACCAACUUCCCCUGGUUU

IGF1R $3^{\prime}$ UTR

$5^{\prime}$

.....UAA(C/U)GGCCUCUCCUCUCGUGCACAUAC......3'

$\operatorname{miR}-455(3782-3788)$

GCUACAUCAGGUUUCCGUGUAU

B IGF1R 3' UTR reporter constructs

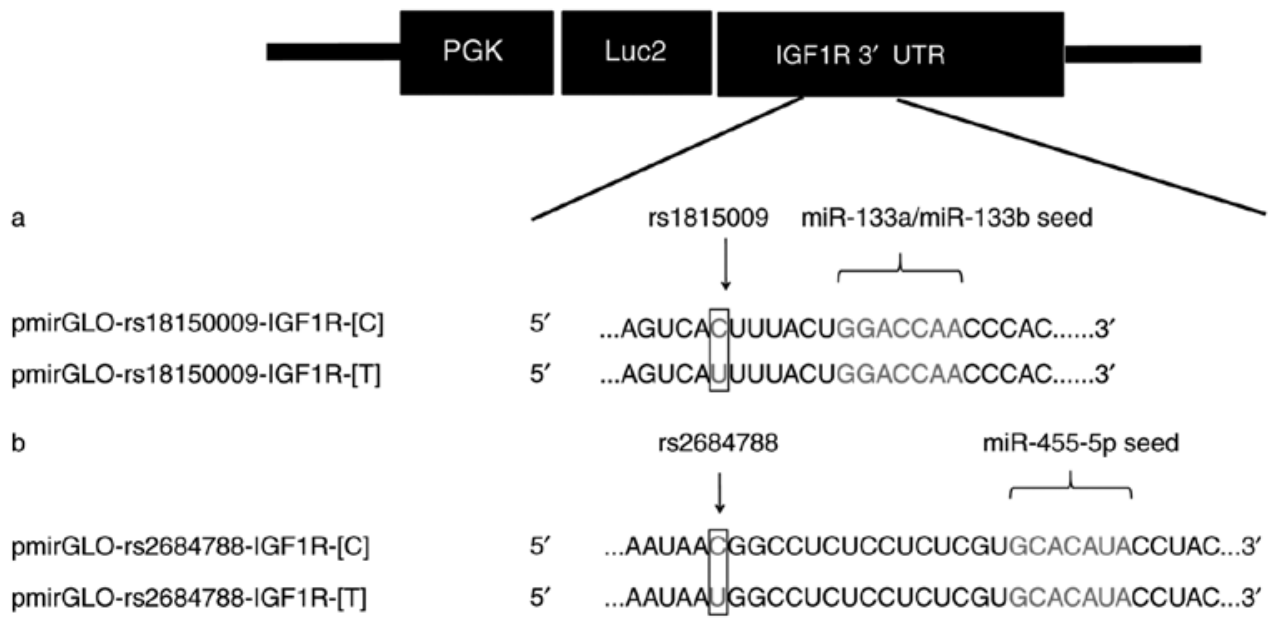

Figure 2. Schematic depiction of miR-133a, miR-133b and miR-455 binding regions within the IGF1R 3'UTR. (A) Schematic representation of the IGF1R 3'UTR according to NCBI reference sequence NM_000875.4 Numbering starts from the first nucleotide of the 3'UTR, SNPs rs1815009 and rs2684788 are present in positions 4000 and 3766, respectively. The seed sequences of miR-133a and miR-133b are located in position 4007-4013, and the seed region of miR-455 is located in the position 3782-3788. (B) Schematic depiction of the constructs used for the luciferase reporter assay. The sequences below demonstrated the nucleotides that are mutated to generate the SNPs (a) rs1815009 and (b) rs2684788 of the C allele (pmirGLO-rs1815009-IGF1R-[C] and pmirGLO-rs2684788-IGF1R-[C]) and T allele (pmirGLO-rs1815009-IGF1R-[T] and pmirGLO-rs2684788-IGF1R-[T]), within the 3'UTR. IGF1R, insulin-like growth factor 1 receptor; 3'UTR, 3' untranslated region; seq, sequence; miR, microRNA; SNP, single nucleotide polymorphism. 
A

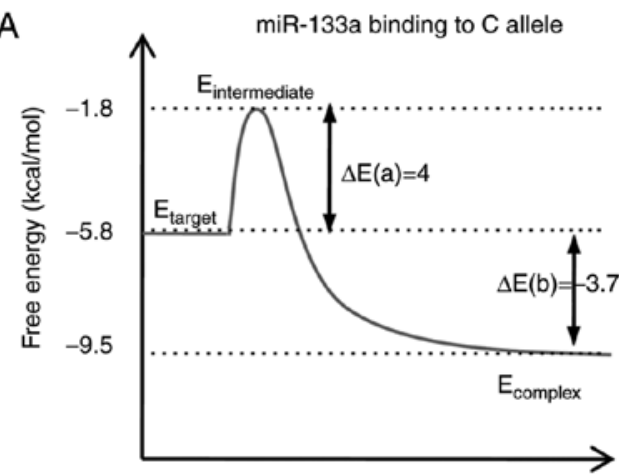

B

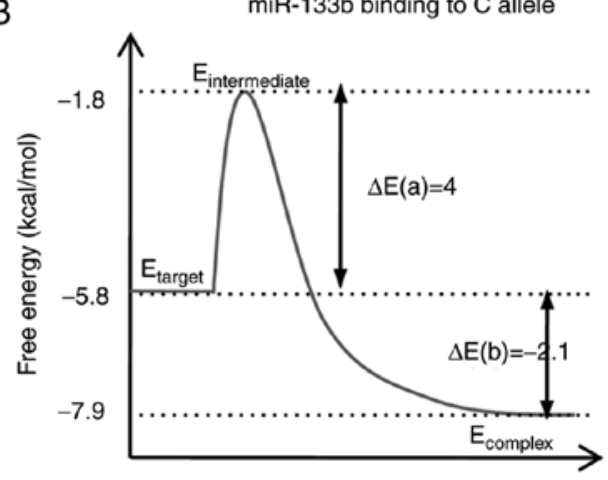

C

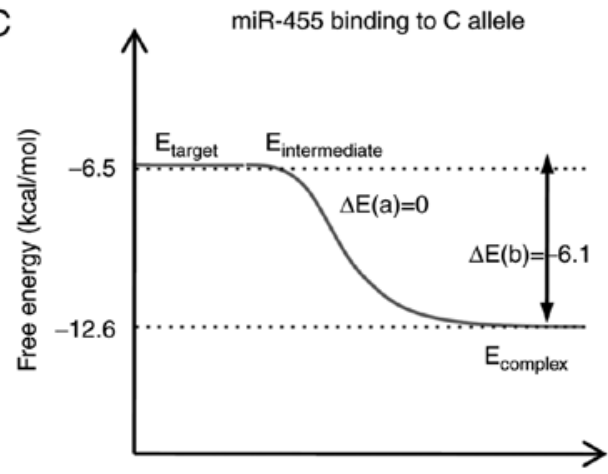

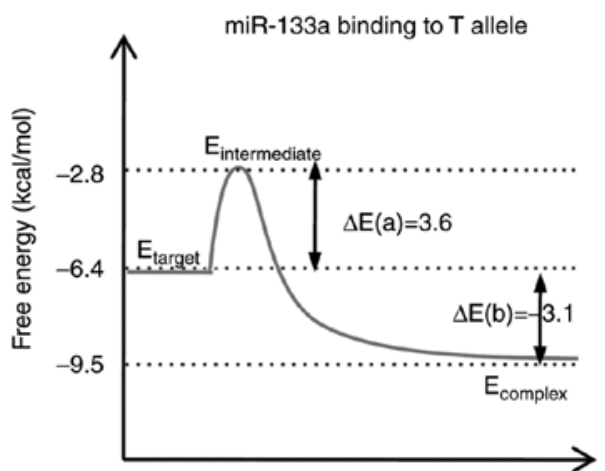
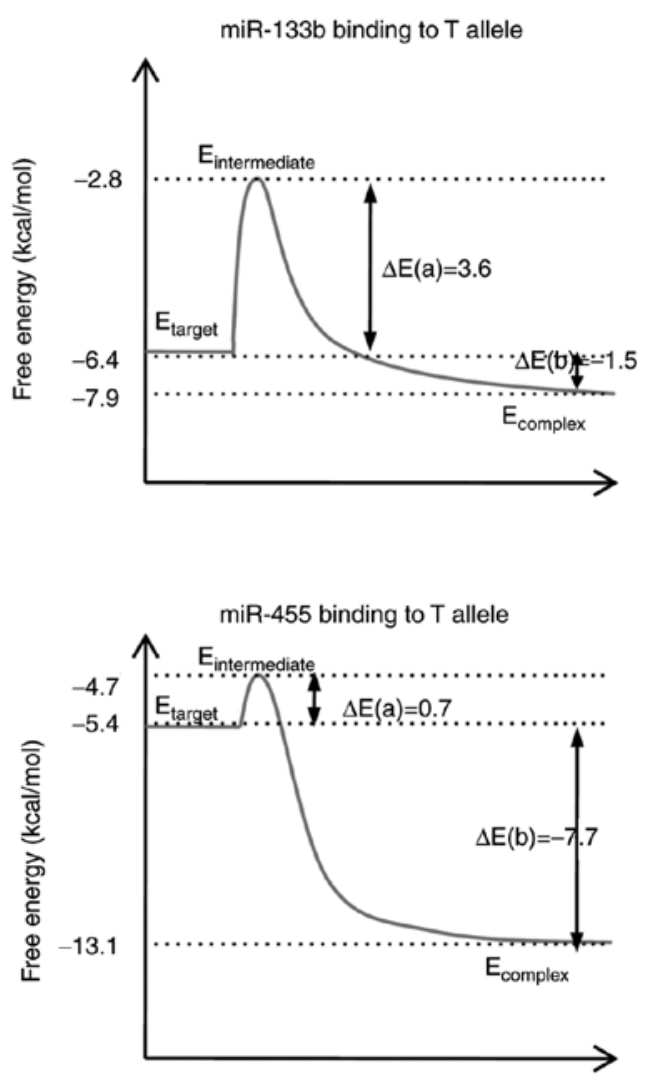

Figure 3. Thermodynamic model of miR-133a, miR-133b and miR-455 binding to the IGF1R 3' untranslated region, and the influence of single nucleotide polymorphisms. The secondary structure-based energies for different miRNA-target binding processes, where the $\Delta \mathrm{E}_{\mathrm{a}}$ is the energy difference between the transition state and the original target, and the $\Delta \mathrm{E}_{\mathrm{b}}$ is the energy difference between the complex and target. Schematic for the binding energy diagram of (A) rs1815009 to miR-133a, (B) rs1815009 to miR-133b, and (C) rs2684788 to miR-455. $\Delta \mathrm{E}_{\mathrm{a}}$, activation energy; $\Delta \mathrm{E}_{\mathrm{b}}$, binding energy; IGF1R, insulin-like growth factor 1 receptor; seq, sequence; miR, microRNA.

variants of SNP rs1815009 (C/T) and rs2684788 (C/T). In order to analyze the binding affinity of miR-133a, miR-133b and miR-455 to the IGF1R 3'UTR of different variants (rs1815009 and rs2684788), a parameter-free thermodynamic model was generated (21). The free energy of secondary structure-based molecules was calculated for each stage of the binding process: $\mathrm{E}_{\text {Target }}$ represents the energy of the dissociated mRNA target region; $\mathrm{E}_{\text {Intermediate }}$ is the energy required to make the target region accessible for miRNA binding; and $\mathrm{E}_{\text {Complex }}$ is the energy of the miRNA-target complex $(6,7,23)$. The activation energy $\left(\Delta \mathrm{E}_{\mathrm{a}}\right)$ was calculated as the difference between $\mathrm{E}_{\text {Intermediate }}$ and $\mathrm{E}_{\text {Target }}$, whereas the binding energy $\left(\Delta \mathrm{E}_{\mathrm{b}}\right)$ was equivalent to the interaction score, which is the difference between $\mathrm{E}_{\text {Complex }}$ and $\mathrm{E}_{\text {Target }}(6,7,23)$. Compared with the $\mathrm{C}$ allele, the $\mathrm{T}$ allele of rs1815009 exhibited a higher $\mathrm{E}_{\text {target }}$ and lower $\Delta \mathrm{E}_{\mathrm{a}}$, indicating that the binding affinity of miR-133a for the $\mathrm{T}$ allele was stronger compared with that of the $\mathrm{C}$ allele. The same phenomenon was observed for miR-133b. A higher $E_{\text {target }}$ and lower $\Delta E_{a}$ was identified for the rs2684788-IGF1R C allele, suggesting that this allele was more accessible for miR-455 binding. Furthermore, the $\Delta E_{b}$ of miR-133a or miR-133b to the rs1815009-IGF1R C allele was increased compared with that of the $\mathrm{T}$ allele, suggesting that miR-133a and miR-133b exhibited a higher binding affinity for the $\mathrm{C}$ allele. Regarding the other SNP, the $\Delta \mathrm{E}_{\mathrm{b}}$ of the rs2684788-IGF1R C allele was reduced compared with that for the $\mathrm{T}$ allele, suggesting that miR-455 exhibited a higher binding affinity for the T allele (Fig. 3). 

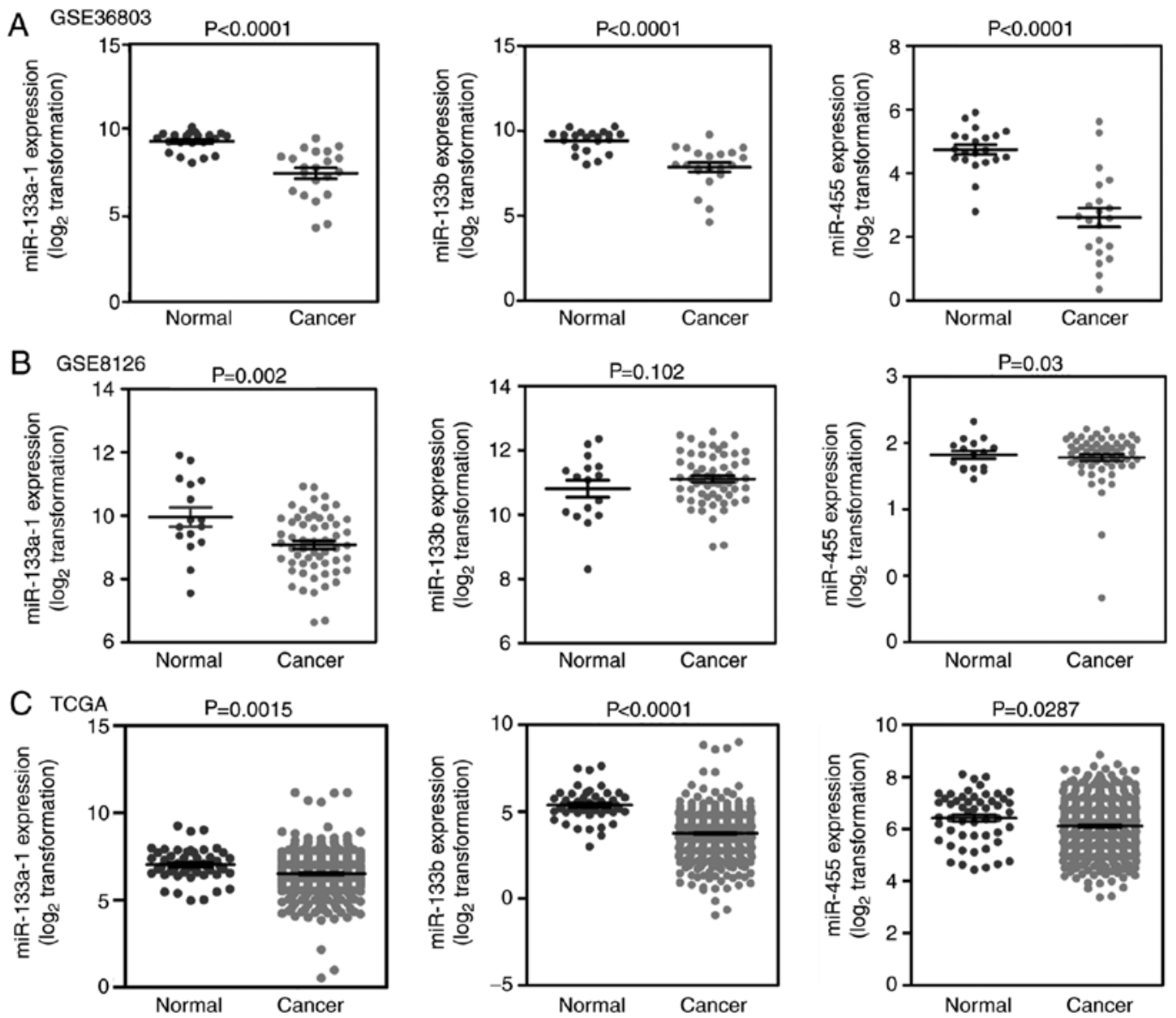

Figure 4. GEO and TCGA data for three miRNAs involved in prostate cancer. (A) Expression of three miRNAs in primary solid tumors (n=21) and normal solid tissue ( $\mathrm{n}=21)$. (B) Expression of three miRNAs in primary and metastatic tumors $(\mathrm{n}=70)$ and normal solid tissue $(\mathrm{n}=16)$. (C) The expression of three miRNAs in primary solid prostate tumor $(\mathrm{n}=498)$ and normal solid tissue $(\mathrm{n}=52)$. Expression values were calculated $\mathrm{using} \log _{2}$-transformed reads/million miRNA mapped values. Data for (A) and (B) was obtained from GEO, and data for (C) was from TCGA. GEO, the Gene Expression Omnibus; TCGA, the Cancer Genome Atlas; miRNA/miR, microRNA.

Expression analysis of miR-133a, miR-133b and $m i R-455$ in GEO and TCGA. According to the inclusion criteria, four datasets [GSE36803 (27), GSE8126 (28), GSE23022 (29) and TCGA datasets] were selected to evaluate the miRNA expression in PCa. However, the GSE23022 dataset is primarily derived from moderately differentiated $\mathrm{PCa}$ samples, unlike the other three datasets which are from primary PCa samples, therefore, this dataset was removed. In total, 579 carcinoma samples and 89 normal samples were included in the present study. With the exception of miR-133b in the GSE8126 dataset, the expression levels of all three miRNAs (miR-133a, miR-133b and miR-455) in PCa tissues were significantly lower compared with that of normal tissues in the three datasets (Fig. 4). This result indicated that miR-133a, miR-133b and miR-455 are likely to be dysregulated in PCa.

Effect of PCa susceptibility polymorphisms rs1815009 and rs2684788 on miRNA binding. An in vitro luciferase reporter assay was performed to verify whether the two SNPs, rs1815009 and rs2684788, are able to affect miRNA binding. For each SNP, pmirGLO constructs were generated carrying the $\mathrm{C}$ or $\mathrm{T}$ allele for rs1815009 and rs 2684788 . These plasmids were designated as pmirGLO-rs1815009-IGF1R-[C] and pmirGLO-rs1815009-IGF1R-[T] for rs1815009, and
pmirGLO-rs2684788-IGF1R-[C] and pmirGLO-rs2684788IGF1R-[C] for rs2684788 (Fig. 2). Each of the pmirGLO constructs was analyzed for luciferase activity levels in 293 cells that overexpressed the predicted interacting miRNAs or the scrambled negative control. When miR-133a or the scrambled negative control was co-transfected with pmirGLO-rs1815009-IGF1R constructs, the luciferase activity for the $\mathrm{C}$ allele was significantly increased compared with the $\mathrm{T}$ allele (Fig. 5A), suggesting a stabilizing rather than inhibitory role, resulting in stronger binding of miR-133a to the rs1815009-IGF1R C allele. Conversely, according to the parameter-free thermodynamic model, it was predicted that the rs1815009-IGF1R C allele may exhibit a higher binding affinity and decreased miR-133b binding energy compared with the $\mathrm{T}$ allele, which was in agreement with the results of the luciferase assay. These results suggest a significantly higher suppressive effect of miR-133b when interacting with the construct containing the $\mathrm{C}$ allele (Fig. 5B). Furthermore, the luciferase assay demonstrated a statistically significant suppressive effect of miR-455 on the construct carrying the $\mathrm{T}$ allele (Fig. $5 \mathrm{C}$ ), indicating that miR-455 had a primary binding efficacy for the rs2684788-IGF1R C allele. Overall, the results of the in vitro luciferase reporter assays were consistent with the MFE prediction. 

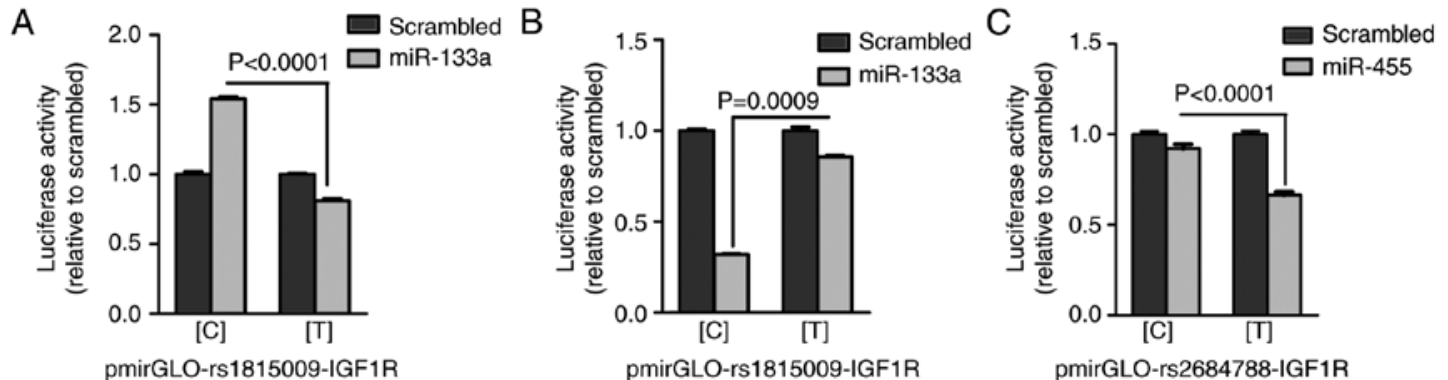

Figure 5. Effect of miRNAs that target the IGF1R 3' untranslated region containing SNP rs1815009 (variants C and T) and rs2684688 (variants C and T). Results from the luciferase assays for (A) miR-133a, (B) miR-133b and (C) miR-455 in 293 cells. The luciferase activity for the pGL3-SNP constructs of rs 1815009 or rs 2684788 co-transfected with the predicted interacting miRNAs or the scrambled negative control (=1). Values represent the average \pm standard error of the mean of three independent experiments performed with three replicates. Statistical significance was calculated using a Student's t-test. IGF1R, insulin-like growth factor 1 receptor; SNP, single nucleotide polymorphism; miRNA/miR, microRNA.

A

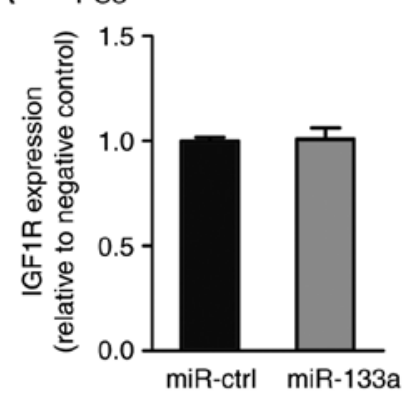

C

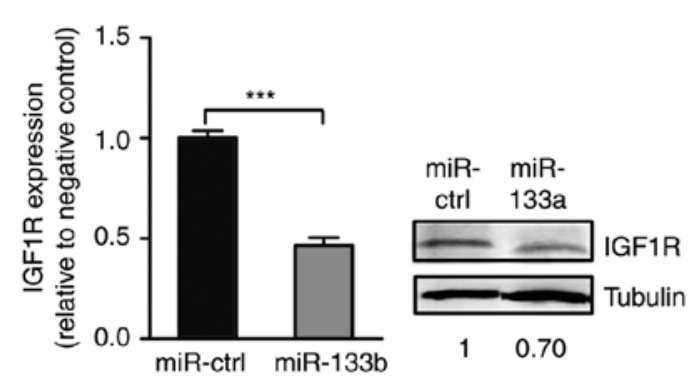

E $\quad$ PC3

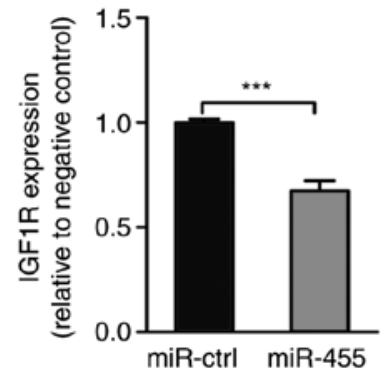

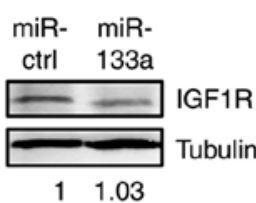

11.03

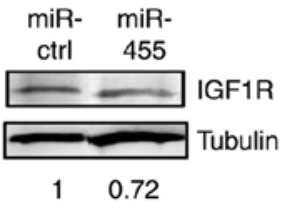

B

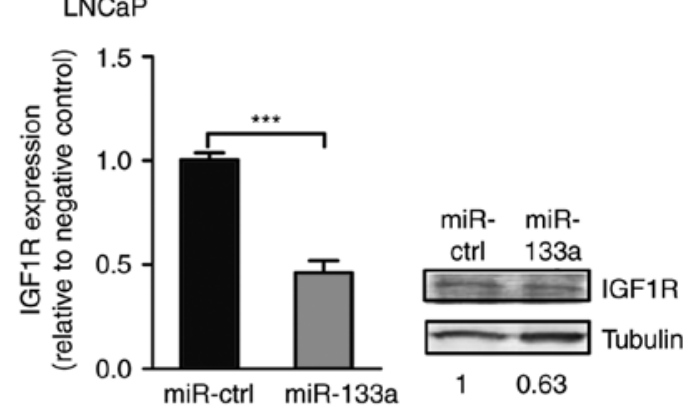

D

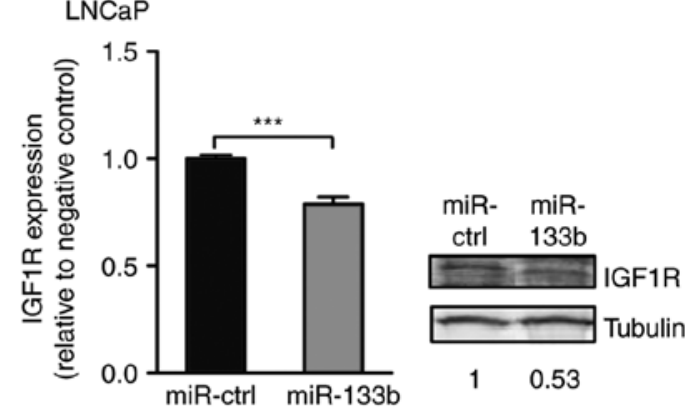

F

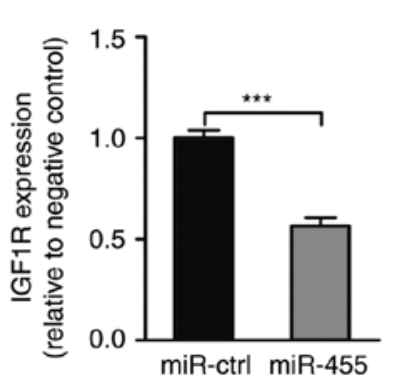

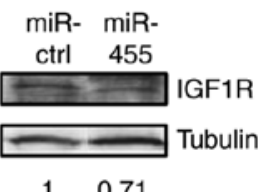

10.71

Figure 6. Effect of miR-133a, miR-133b or miR-455 overexpression on IGF1R at the mRNA and protein levels. Results for the RT-qPCR and western blot analyses for miR-133a in (A) PC3 and (B) LNCaP cells; for miR-133b in (C) PC3 and (D) LNCaP cells; and miR-4 55 in (E) PC3 and (F) LNCaP cells. RT-qPCR analysis of IGF1R is represented as relative expression in the cells transfected with pre-133a, pre-133b, pre-455 or a scrambled negative control, and the data were analyzed using $\beta$-actin as an endogenous control for normalization. The western blots demonstrated the IGF1R protein in the cells transfected with pre-133a, pre-133b, pre-455 or a scrambled negative control. The numbers represent the relative band intensities, measured by densitometry analysis and normalized using tubulin as an endogenous control. Statistical significance was calculated using a Student's t-test. ${ }^{* * *} \mathrm{P}<0.001$. IGF1R, insulin-like growth factor 1 receptor; miR, microRNA; RT-qPCR, reverse transcription-quantitative polymerase chain reaction; ctrl, control.

Overexpression of miRNAs affect the IGFIR $m R N A$ and protein expression levels. To determine the effect of rs1815009 and rs 2684788 on the mRNA and protein expression levels of endogenous IGF1R in vitro, $\mathrm{PCa}$ cell lines (PC3 and LNCaP) were transfected with miRNA precursors of the interacting miRNAs. RT-qPCR analysis demonstrated that, with the 
A

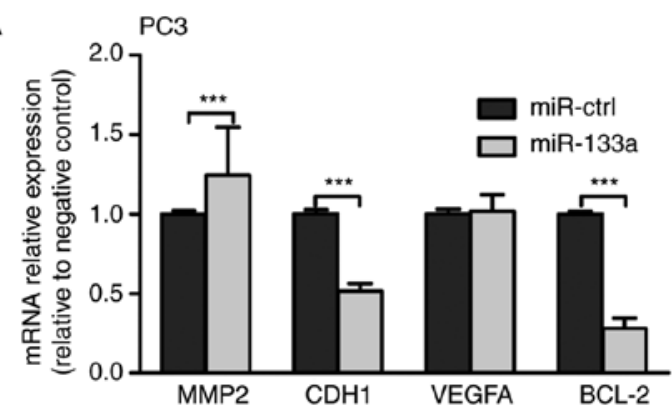

C

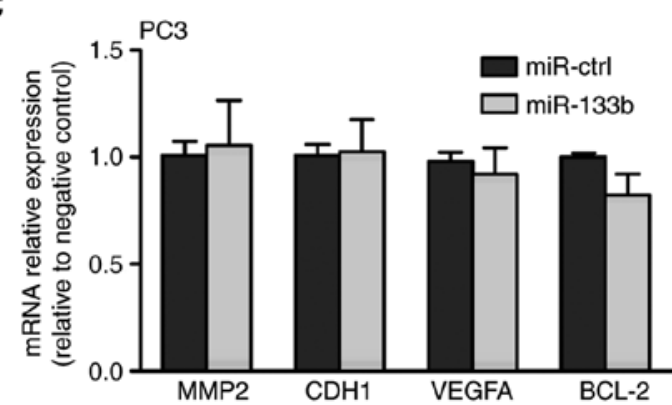

E

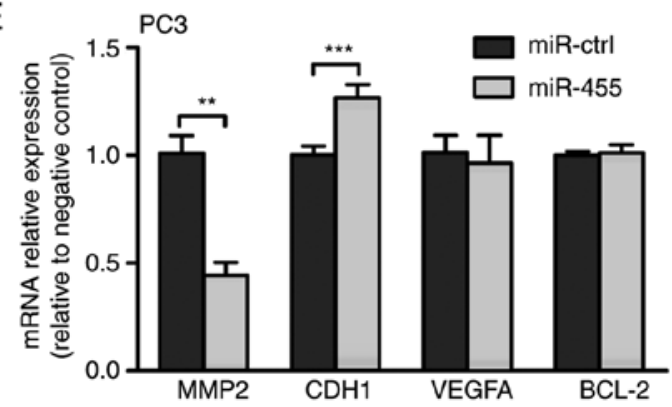

B

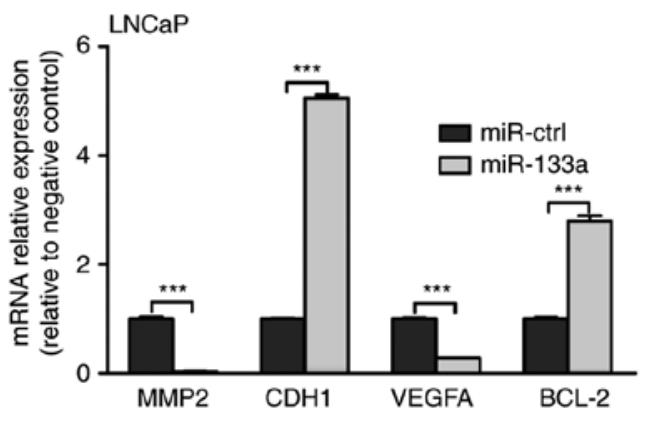

D
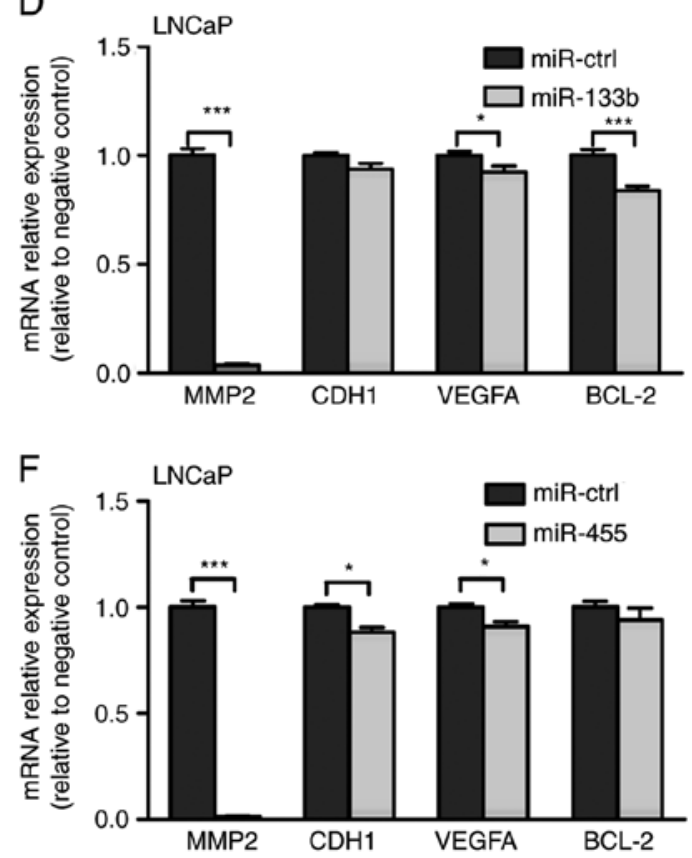

Figure 7. Effect of miR-133a, miR-133b or miR-455 overexpression on the transcription of genes associated with the biological function of tumors. Results from reverse transcription-quantitative polymerase chain reaction analysis of MMP2, CDH1, VEGFA, BCL-2 in PC3 cells transfected with (A) pre-133a, (C) pre-133b and (E) pre-455, and in LNCaP cells transfected with (B) pre-133a, (D) pre-133b and (F) pre-455, using GAPDH as an endogenous control for normalization. Statistical significance was calculated using a Student's t-test. ${ }^{*} \mathrm{P}<0.05,{ }^{* *} \mathrm{P}<0.01$ and ${ }^{* * *} \mathrm{P}<0.001$. MMP2, matrix metalloproteinase-2; CDH1, E-cadherin; VEGFA, vascular endothelial growth factor A; BCL2, B-cell lymphoma-2; GAPDH, glyceraldehyde-phosphate dehydrogenase; miR, micro-RNA; ctrl, control.

exception of overexpression of miR-133a in PC3 cells, forced expression of the interacting miRNAs significantly suppressed IGF1R expression at the transcriptional level in PCa cells (PC3 and LNCaP) compared with the miR-control (Fig. 6). In addition, western blot analysis demonstrated that miR-133b markedly downregulated the expression of the IGF1R protein in LNCaP cells containing the rs2684788-IGF1R $\mathrm{C}$ allele (Fig. 6D, right). A similar suppressive effect was observed in PC3 cells that overexpressed miR-455 (Fig. 6E, right). Taken together, these results suggest that miR-133b directly regulates IGF1R gene expression at the mRNA and protein levels in LNCaP cells, whereas miR-133a regulates IGF1R gene expression at the mRNA level in LNCaP cells, but not in PC3 cells. Therefore, the rs 2684788 SNP exhibited a functional effect on the miR-455 binding efficacy in PC3 cells.

Overexpression of miRNAs affect genes associated with invasion, migration and apoptosis at the mRNA levels. In order to analyze the effect of miR-133a, miR-133b and miR-455 on the expression of genes associated with the biological activity of tumors, including cell invasion, migration and apoptosis,
miRNA precursors (pre-133a, pre-133b, pre-455 or scrambled negative control) were transfected into PC3 and LNCaP cell lines. Expression levels were determined $48 \mathrm{~h}$ after transfection. Matrix metalloproteinase 2 (MMP-2) in transfected LNCaP cells was demonstrated to be significantly suppressed by miR-133a, miR-133b and miR-455, and was suppressed by miR-455 in PC3 cells compared with the miR-control. E-cadherin (CDH1) was significantly upregulated in LNCaP cells that overexpressed miR-133a, and in PC3 cells that overexpressed miR-455, but exhibited mild downregulation in LNCaP cells that overexpressed miR-455 compared with the miR-control. Forced expression of miR-133b and miR-455 in LNCaP cells resulted in mild suppression of vascular endothelial growth factor A (VEGFA), but the overexpression of miR-133a in LNCaP cells led to a more significant downregulation at the transcriptional level. B-cell lymphoma-2 (BCL-2) was significant upregulated in $\mathrm{LNCaP}$ cells with forced expression of miR-133a, but a suppressive effect was observed in post-transfected LNCaP cells that overexpressed miR-133b compared with the miR-control. These results are presented in Fig. 7. 
A

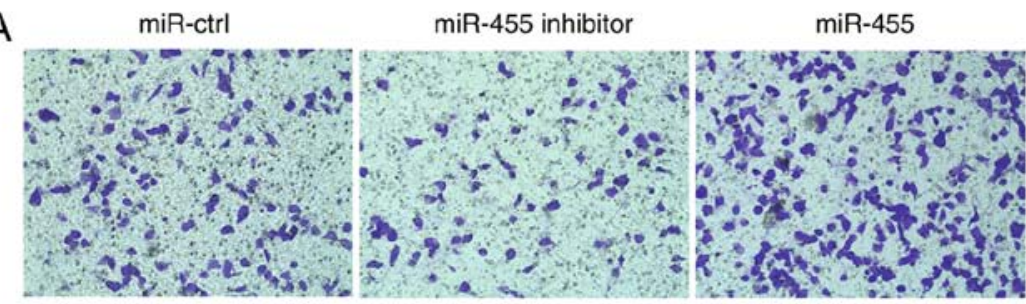

B

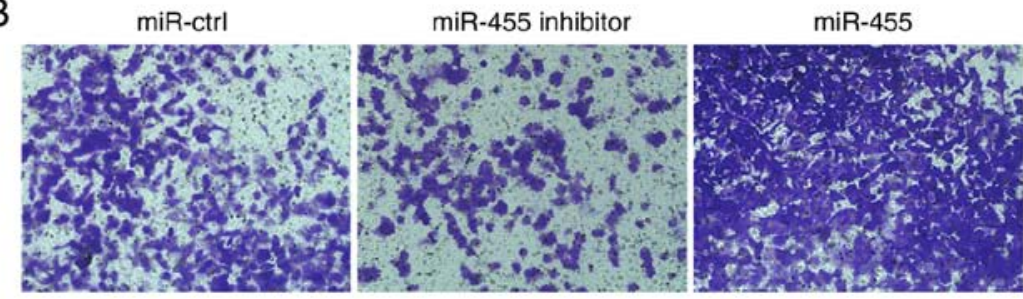

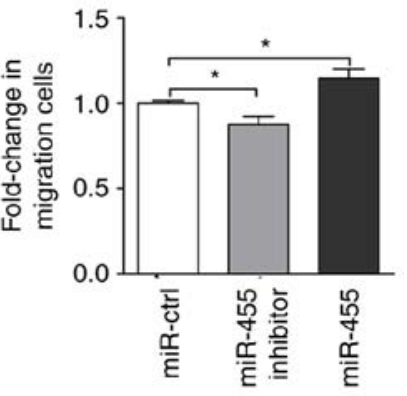

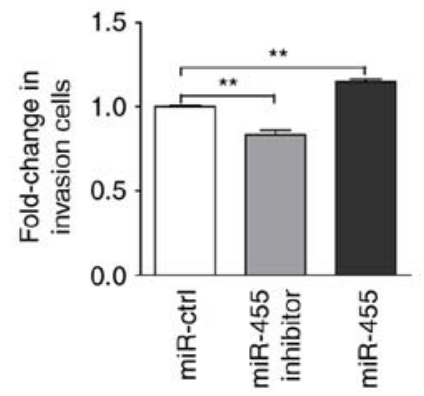

Figure 8. miR-455 enhances the migratory and invasive abilities of LNCaP cells. Values of cell migration and invasion were calculated according to the OD570 values of LNCaP cells on the lower surface extracted using acetic acid. (A) After $48 \mathrm{~h}$-incubation, post-transfected LNCaP cells migrated to the bottom surface of the Transwell membrane for the migration assay. (B) After 72 h-incubation, post-transfected LNCaP cells migrated to the bottom surface of the Transwell membrane pre-coated with Matrigel for the invasion assay. Cells were imaged at x 20 magnification. Statistical significance was calculated using a Student's t-test. ${ }^{*} \mathrm{P}<0.05$ and ${ }^{* *} \mathrm{P}<0.01$. miR, microRNA; ctrl, control.

miR-455 enhances cell migration and invasion in LNCaP cells. To analyze the effect of miR-455 on prostate cells migration and invasion, post-transfected LNCaP cells were harvested to a Transwell assay was performed. After $48 \mathrm{~h}$ incubation, the migration rate was significantly increased in LNCaP cells with miR-455 overexpression, and significantly suppressed in cells that were treated with miR-455 inhibitor compared with the miR-control (Fig. 8A). Similarly, after $72 \mathrm{~h}$ incubation, the invasion rate in LNCaP cells with miR-455 overexpression was significantly increased, and significantly decreased in LNCaP cells treated with miR-455 inhibitor compared with the miR-control (Fig. 8B).

\section{Discussion}

Polymorphisms in miRNA target binding sites affect the binding efficacy of miRNAs. Consequently, the miRNA binding affinity for the target may be affected, which may potentially alter the expression of the target gene, thereby contributing to the susceptibility for developing certain diseases. Indeed, genetic polymorphisms that alter miRNA binding have been associated with disease risk in multiple studies $(6,7,9,12,13)$. From an association analysis based on the GWAS data of ChinaPCa, we previously identified two SNPs (rs1815009 and 2684788) in the IGF1R 3'UTR with significant genotype distribution between $\mathrm{PCa}$ and control samples (18). IGF1R serves an important role in the risk and progression of $\mathrm{PCa}(16,17)$. In the present study, bioinformatics analysis was used, which revealed that rs1815009 is located near the binding seed regions of miR-133a and miR-133b, and rs2684788 is located near the binding seed region of miR-455. In addition, the binding affinity of these three miRNAs was altered by different alleles, as predicted using a parameter-free thermodynamic model (21). The expression of miR-133a, miR-133b and miR-455 from three miRNA profiling datasets in GEO and TCGA demonstrated a significant difference between PCa and normal tissues. The in vitro luciferase reporter assays further confirmed the binding affinity of these three miRNAs, which was altered by different alleles. In PC3 cells, overexpression of the three miRNAs resulted in suppression of VEGFA, with the overexpression of miR-133a leading to the most significant level of downregulation at the transcriptional level in LNCaP cells.

There are two copies of miR-133a, miR-133a-1 and miR-133a-2, located on chromosomes 18q11.2 and 20q13.33, respectively (28). miR-133 has been demonstrated as a potent suppressor of non-muscle expression of genes involved in cell fate determination during mouse and human embryonic stem cell differentiation (30). miR-133a inhibits cell proliferation, migration and invasion in PCa cells by targeting the epidermal growth factor receptor (31). In the present study, miR-133a in $\mathrm{PCa}$ tissues demonstrated lower expression in a large number of samples from GEO and TCGA, and this result was consistent with a previous report (32). Gong et al (33) reported that miR-133a was downregulated in gastric cancer, and functions as a tumor suppressor in vitro and in vivo, partly by repressing IGF1R. Guo et al (34) reported that miR-133a overexpression repressed IGF1R 3'UTR reporter activity, and reduced the mRNA and protein levels of endogenous IGF1R in ovarian cancer. Other studies have also suggested that IGF1R is a potential target of miR-133a (35). In the present research, miR-133a was predicted to bind to the IGF1R ' UTR. It was demonstrated that the overexpression of miR-133a downregulated the mRNA expression of IGF1R in LNCaP cells in the current study. The MFE indicated that the $\mathrm{C}$ allele for rs1815009 had greater accessibility for miR-133a binding compared with the $\mathrm{T}$ allele, 
which was consistent with the results of luciferase reporter assays. In addition, a population-based study on the ChinaPCa revealed that the $\mathrm{C}$ allele for $\mathrm{rs} 1815009$ was a common variant with a higher frequency among the cases with PCa, and a lower frequency among the healthy individuals. This suggests that the rs $1815009 \mathrm{C}$ allele is a crucial risk factor for $\mathrm{PCa}$, via differential regulation of IGF1R with miR-133a.

miR-133b, located on chromosome $6 \mathrm{p} 12.2$ (36), is generally considered to be a muscle-specific molecule that enhances myoblast differentiation (37). Although miR-133a and $\mathrm{miR}-133 \mathrm{~b}$ are located on different chromosomes in the human genome, they have common target genes, including IGF1R, and are merely distinguished by a single nucleotide at the $3^{\prime}$ end. Previous studies have demonstrated that miR-133b serves a crucial role in malignant tumors and non-muscle related diseases (38-40), including PCa (40). miR-133b expression was revealed to be significantly lower in colorectal carcinoma tissues compared with healthy colon tissues and adjacent non-tumor tissues, modulating cell apoptosis and invasion in colorectal carcinoma (41). In the present study, the expression of miR-133b in PCa tissue was lower compared with that of normal controls in large samples obtained from GEO and TCGA. miR-133b may serve an important role as a tumor suppressor gene in osteosarcoma and overexpression of miR-133b has been reported to decrease the expression of IGF1R (42). miR-133b was predicted to bind to the IGF1R 3'UTR in the current study. Furthermore, miR-133b was observed to bind more tightly to the $\mathrm{C}$ allele of rs1815009 within the IGF1R 3'UTR using a thermodynamic model. Subsequently, the miR-133b target region within the IGF1R 3'UTR and the binding affinity were validated, in which miR-133b exhibited greater suppression of the $\mathrm{C}$ allele compared with the $\mathrm{T}$ allele, as measured using a dual-luciferase reporter assay. In addition, the population-based study by ChinaPCa revealed the $\mathrm{C}$ allele for rs1815009 was a common variant with a higher frequency among the cases with $\mathrm{PCa}$, and exhibited at a lower frequency among the healthy population. Together with the results of IGF1R expression at the mRNA and protein levels, these results suggest that the $\mathrm{C}$ allele differentially regulates IGF1R with miR-133b. Therefore, the C allele for rs1815009 is a key risk factor for PCa through binding with miR-133a or miR-133b.

miR-455-5p is located on chromosome 6 , and accumulating evidence suggests that miR-455 serves essential roles in human cancer. Sand et al (43) identified 16 significantly upregulated miRNAs, including miR-455-5p, in basal cell carcinoma. Lv et al (41) demonstrated that miR-455-5p was significantly upregulated in thymic epithelial tumor tissues. However, miR-455 was reported to be significantly downregulated in a colon cancer sample, and overexpression of miR-455 significantly inhibited the proliferation and invasion of SW480 cells, but had no evident effect on apoptosis (44). Pantaleo et al (45) identified seven miRNAs, including miR-455-5p that may alter IGF1R expression by targeting the IGF1R 3'UTR in gastrointestinal stromal tumor. The results for IGF1R expression at the protein level suggested a significant suppressive effect in PC3 cells containing the IGF1R-rs2684788 T allele, but not in LNCaP cells carrying the IGF1R-rs2684788 C allele. In addition, the population-based study of China $\mathrm{PCa}$ revealed that the $\mathrm{T}$ allele for rs2684788 was a common variant with a higher frequency among the cases with $\mathrm{PCa}$, but exhibited at a lower frequency among the healthy population. Along with the results for IGF1R expression at the gene and protein levels, suggesting that the $\mathrm{T}$ allele of rs2684788 is a key risk factor for PCa through altered regulation of IGF1R by miR-455, as observed for prostate carcinoma.

MMP-2, one of the key enzymes involved in extracellular matrix (ECM) degradation, serves an essential role in the invasion and metastasis of various cancer types $(46,47)$, and is significantly associated with the malignancy and metastasis of $\mathrm{PCa}$ (47). CDH1 gene, encoding the E-cadherin protein, is associated with infiltrative tumor growth patterns and lymph node metastasis in colorectal cancer (48). Abnormal CDH1 expression has been associated with numerous human diseases, including PCa (49). VEGFA, a key angiogenic factor, induces endothelial cell proliferation, differentiation and migration, thus making VEGFA an important molecule in angiogenesis (50). The oncogene BCL-2, a repressor of apoptosis, has been reported to be upregulated in numerous cancer types (51). Elevated expression of BCL-2 is highly protective against apoptosis in vitro, resulting in resistance to androgen depletion in vivo (52). In the present study, the expression levels of MMP-2 and VEGFA were downregulated in LNCaP cells that overexpressed miR-133a, miR-133b or miR-455. Furthermore, miR-133a and miR-133b have been identified to be associated with the migration and invasion of androgen-insensitive human PCa cells (31). In the present study, miR-455 was also demonstrated to serve a role in the migration and invasion of $\mathrm{LNCaP}$ cells that are androgen-sensitive. Notably, MMP2 expression was regulated by mir-133b and mir-455. The expression level and activity of MMP2/9 have been revealed to be regulated by ERK1/2 in 293 and monocytic cells (53). In addition, aberrant miR-455-5p expression is partially regulated by activated ERK signaling in non-small cell lung cancer (54). It is possible that ERK1/2 regulates MMP2 by miR-455 in LNCaP cells. Future studies should focus on identifying drugs, which are able to target this process.

In conclusion, two miRNA binding prediction tools were used to predict the miRNAs that bind to the IGF1R 3'UTR, and revealed that rs $1815009(\mathrm{C} / \mathrm{T})$ overlaps miR-133a and $\mathrm{miR}-133 \mathrm{~b}$, and rs2684788 (C/T) overlaps the predicted miR-455 binding site in the IGF1R 3'UTR. Predictions from a thermodynamic model for miRNA-target interaction and the results from the luciferase reporter assay were integrated to demonstrate that miR-133a and miR-133b may bind near rs1815009, and miR-455 near rs2684788, in the IGF1R 3'UTR. In addition, public data analysis revealed that miR-133a, miR-133b and miR-455 demonstrated significantly lower expression in $\mathrm{PCa}$ tissue in the majority of public datasets. Furthermore, overexpression of miR-455 significantly increased the migration and invasion rates in LNCaP cells. The results of the present study revealed that the association between rs1815009, rs2684788 and PCa risk involves altered miRNA regulation. It may be suggested that miR-133a, miR-133b and miR-455 are useful diagnostic markers for PCa. However, future in vivo studies are required to confirm the results of the current study.

\section{Acknowledgements}

Not applicable. 


\section{Funding}

The present study was supported by grants from the National Natural Science Foundation of China (grant nos. 81272853, 81472414, 81370857, 81360378 and 81460388), the Guangxi Scientific Research and Technology Development Project (grant nos. 2013BC26299 and 1355005-3-17) and the Guangxi Natural Science Foundation (grant nos. 2015GXNSFBB139008, 2014GXNSFBA118201 and 2013GXNSFFA019002), and the Youth Science Foundation of Guangxi Medical University (grant nos. GXMUYSF201201 and GXMUYSF201603).

\section{Availability of data and materials}

All data generated or analyzed during this study are included in this published article.

\section{Authors' contributions}

HW, WH, YaH and QZ designed the study; HW, WH, XY and $\mathrm{YuH}$ performed the experiments; HW, ZM, YaH, WL and YG analyzed the data; and HW, XY, YaH and ZM wrote the manuscript. All authors reviewed and approved the final manuscript.

\section{Ethics approval and consent to participate}

Not applicable.

\section{Patient consent for publication}

Not applicable.

\section{Competing interests}

The authors declare that they have no competing interests.

\section{References}

1. Torre LA, Bray F, Siegel RL, Ferlay J, Lortet-Tieulent J and Jemal A: Global cancer statistics, 2012. CA Cancer J Clin 65: 87-108, 2015.

2. Siegel RL, Miller KD and Jemal A: Cancer statistics, 2016. CA Cancer J Clin 66: 7-30, 2016.

3. Chen W, Zheng R, Baade PD, Zhang S, Zeng H, Bray F, Jemal A, $\mathrm{Yu}$ XQ and He J: Cancer statistics in China, 2015. CA Cancer J Clin 66: 115-132, 2016.

4. Bratt O: What should a urologist know about hereditary predisposition to prostate cancer? BJU Int 99: 743-748, 2007.

5. Stegeman S, Amankwah E, Klein K, O'Mara TA, Kim D, Lin HY, Permuth-Wey J, Sellers TA, Srinivasan S, Eeles R, et al: A large-scale analysis of genetic variants within putative miRNA binding sites in prostate cancer. Cancer Discov 5: 368-379, 2015

6. Zhang L, Liu Y, Song F, Zheng H, Hu L, Lu H, Liu P, Hao X, Zhang $\mathrm{W}$ and Chen K: Functional SNP in the microRNA-367 binding site in the 3 'UTR of the calcium channel ryanodine receptor gene $3(R Y R 3)$ affects breast cancer risk and calcification. Proc Natl Acad Sci USA 108: 13653-13658, 2011.

7. Minguzzi S, Selcuklu SD, Spillane C and Parle-McDermott A: An NTD-associated polymorphism in the 3'UTR of MTHFD1L can affect disease risk by altering miRNA binding. Hum Mutat 35: 96-104, 2014.

8. Cheng CJ, Bahal R, Babar IA, Pincus Z, Barrera F, Liu C, Svoronos A, Braddock DT, Glazer PM, Engelman DM, et al: MicroRNA silencing for cancer therapy targeted to the tumour microenvironment. Nature 518: 107-110, 2015.
9. Nicoloso MS, Sun H, Spizzo R, Kim H, Wickramasinghe P, Shimizu M, Wojcik SE, Ferdin J, Kunej T, Xiao L, et al: Single-nucleotide polymorphisms inside microRNA target sites influence tumor susceptibility. Cancer Res 70: 2789-2798, 2010.

10. Chandradoss SD, Schirle NT, Szczepaniak M, MacRae IJ and Joo C: Dynamic search process underlies MicroRNA targeting. Cell 162: 96-107, 2015.

11. Zhang L, Zhang S, Yao J, Lowery FJ, Zhang Q, Huang WC, Li P, Li M, Wang X, Zhang C, et al: Microenvironment-induced PTEN loss by exosomal microRNA primes brain metastasis outgrowth. Nature 527: 100-104, 2015.

12. Kuosmanen SM, Viitala S, Laitinen T, Peräkylä M, Pölönen $P$, Kansanen E, Leinonen H, Raju S, Wienecke-Baldacchino A, Närvänen A, et al: The effects of sequence variation on genome-wide NRF2 binding-new target genes and regulatory SNPs. Nucleic Acids Res 44: 1760-1775, 2016.

13. Niu T, Liu N, Zhao M, Xie G, Zhang L, Li J, Pei YF, Shen H, $\mathrm{Fu}$ X, He H, et al: Identification of a novel FGFRL1 MicroRNA target site polymorphism for bone mineral density in meta-analyses of genome-wide association studies. Hum Mol Genet 24: 4710-4727, 2015.

14. Ullrich A, Gray A, Tam AW, Yang-Feng T, Tsubokawa M, Collins C, Henzel W, Le Bon T, Kathuria S, Chen E, et al: Insulin-like growth factor I receptor primary structure: Comparison with insulin receptor suggests structural determinants that define functional specificity. EMBO J 5: 2503-2512, 1986.

15. Ofer P, Heidegger I, Eder IE, Schöpf B, Neuwirt H, Geley S, Klocker $\mathrm{H}$ and Massoner P: Both IGF1R and INSR knockdown exert antitumorigenic effects in prostate cancer in vitro and in vivo. Mol Endocrinol 29: 1694-1707, 2015.

16. Wang X, Huang Y, Christie A, Bowden M, Lee GS, Kantoff PW and Sweeney CJ: Cabozantinib inhibits abiraterone's upregulation of IGFIR phosphorylation and enhances its anti-prostate cancer activity. Clin Cancer Res 21: 5578-5587, 2015.

17. Madan RA and Dahut WL: Prostate cancer: Charting a course in metastatic castration-sensitive prostate cancer. Nat Rev Urol 12: 368-369, 2015.

18. Chen Y, Xin X, Li J, Xu J, Yu X, Li T, Mo Z and Hu Y: RTK/ERK pathway under natural selection associated with prostate cancer. PLoS One 8: e78254, 2013.

19. Agarwal V, Bell GW, Nam JW and Bartel DP: Predicting effective microRNA target sites in mammalian mRNAs. Elife 4, 2015. doi: $10.7554 /$ eLife. 05005 .

20. Betel D, Koppal A, Agius P, Sander C and Leslie C: Comprehensive modeling of microRNA targets predicts functional non-conserved and non-canonical sites. Genome Biol 11: R90, 2010.

21. Mathews DH, Disney MD, Childs JL, Schroeder SJ, Zuker M and Turner DH: Incorporating chemical modification constraints into a dynamic programming algorithm for prediction of RNA secondary structure. Proc Natl Acad Sci USA 101: 7287-7292, 2004.

22. Turner DH and Mathews DH: NNDB: The nearest neighbor parameter database for predicting stability of nucleic acid secondary structure. Nucleic Acids Res 38: D280-D282, 2010.

23. Kertesz M, Iovino N, Unnerstall U, Gaul U and Segal E: The role of site accessibility in microRNA target recognition. Nat Genet 39: 1278-1284, 2007.

24. Barrett T, Troup DB, Wilhite SE, Ledoux P, Rudnev D, Evangelista C, Kim IF, Soboleva A, Tomashevsky M, Marshall KA, et al: NCBI GEO: Archive for high-throughput functional genomic data. Nucleic Acids Res 37: D885-D890, 2009.

25. Livak KJ and Schmittgen TD: Analysis of relative gene expression data using real-time quantitative PCR and the $2^{-\Delta \Delta C_{\mathrm{T}}}$ method. Methods 25: 402-408, 2001.

26. Lin HH, Liao CJ, Lee YC, Hu KH, Meng HW and Chu ST: Lipocalin-2-induced cytokine production enhances endometrial carcinoma cell survival and migration. Int J Biol Sci 7: 74-86, 2011.

27. Lin PC, Chiu YL, Banerjee S, Park K, Mosquera JM, Giannopoulou E, Alves P, Tewari AK, Gerstein MB, Beltran H, et al: Epigenetic repression of miR-31 disrupts androgen receptor homeostasis and contributes to prostate cancer progression. Cancer Res 73: 1232-1244, 2013.

28. Ambs S, Prueitt RL, Yi M, Hudson RS, Howe TM, Petrocca F, Wallace TA, Liu CG, Volinia S, Calin GA, et al: Genomic profiling of microRNA and messenger RNA reveals deregulated microRNA expression in prostate cancer. Cancer Res 68: 6162-6170, 2008. 
29. Wach S, Nolte E, Szczyrba J, Stöhr R, Hartmann A, Ørntoft T, Dyrskjøt L, Eltze E, Wieland W, Keck B, et al: MicroRNA profiles of prostate carcinoma detected by multiplatform microRNA screening. Int J Cancer 130: 611-621, 2012.

30. Ivey KN, Muth A, Arnold J, King FW, Yeh RF, Fish JE, Hsiao EC, Schwartz RJ, Conklin BR, Bernstein HS, et al: MicroRNA regulation of cell lineages in mouse and human embryonic stem cells. Cell Stem Cell 2: 219-229, 2008

31. Tao J, Wu D, Xu B, Qian W, Li P, Lu Q, Yin C and Zhang W: microRNA-133 inhibits cell proliferation, migration and invasion in prostate cancer cells by targeting the epidermal growth factor receptor. Oncol Rep 27: 1967-1975, 2012.

32. Kojima S, Chiyomaru T, Kawakami K, Yoshino H, Enokida H, Nohata N, Fuse M, Ichikawa T, Naya Y, Nakagawa M, et al: Tumour suppressors miR-1 and miR-133a target the oncogenic function of purine nucleoside phosphorylase (PNP) in prostate cancer. Br J Cancer 106: 405-413, 2012.

33. Gong Y, Ren J, Liu K and Tang LM: Tumor suppressor role of miR-133a in gastric cancer by repressing IGF1R. World J Gastroenterol 21: 2949-2958, 2015.

34. Guo J, Xia B, Meng F and Lou G: miR-133a suppresses ovarian cancer cell proliferation by directly targeting insulin-like growth factor 1 receptor. Tumour Biol 35: 1557-1564, 2014.

35. Zhang W, Liu K, Liu S, Ji B, Wang Y and Liu Y: MicroRNA-133a functions as a tumor suppressor by targeting IGF-1R in hepatocellular carcinoma. Tumour Biol 36: 9779-9788, 2015.

36. Mitchelson KR and Qin WY: Roles of the canonical myomiRs miR-1, -133 and -206 in cell development and disease. World J Biol Chem 6: 162-208, 2015.

37. Rao PK, Kumar RM, Farkhondeh M, Baskerville $S$ and Lodish HF: Myogenic factors that regulate expression of muscle-specific microRNAs. Proc Natl Acad Sci USA 103: 8721-8726, 2006.

38. Liu L, Shao X, Gao W, Zhang Z, Liu P, Wang R, Huang P, Yin Y and Shu Y: MicroRNA-133b inhibits the growth of non-small-cel lung cancer by targeting the epidermal growth factor receptor. FEBS J 279: 3800-3812, 2012.

39. Duan FT, Qian F, Fang K, Lin KY, Wang WT and Chen YQ miR-133b, a muscle-specific microRNA, is a novel prognostic marker that participates in the progression of human colorectal cancer via regulation of CXCR4 expression. Mol Cancer 12: 164 2013.

40. Karatas OF, Guzel E, Suer I, Ekici ID, Caskurlu T, Creighton CJ, Ittmann $\mathrm{M}$ and Ozen M: miR-1 and miR-133b are differentially expressed in patients with recurrent prostate cancer. PLoS One 9: e98675, 2014

41. Lv LV, Zhou J, Lin C, Hu G, Yi LU, DU J, Gao K and Li X: DNA methylation is involved in the aberrant expression of miR-133b in colorectal cancer cells. Oncol Lett 10: 907-912, 2015.
42. Zhao H, Li M, Li L, Yang X, Lan G and Zhang Y: MiR-133b is down-regulated in human osteosarcoma and inhibits osteosarcoma cells proliferation, migration and invasion, and promotes apoptosis. PLoS One 8: e83571, 2013.

43. Sand M, Skrygan M, Sand D, Georgas D, Hahn SA, Gambichler T, Altmeyer P and Bechara FG: Expression of microRNAs in basal cell carcinoma. Br J Dermatol 167: 847-855, 2012.

44. Hu J, Xu Y and Cai S: Specific microRNAs as novel biomarkers for combination chemotherapy resistance detection of colon adenocarcinoma. Eur J Med Res 20: 95, 2015.

45. Pantaleo MA, Ravegnini G, Astolfi A, Simeon V, Nannini M, Saponara M, Urbini M, Gatto L, Indio V, Sammarini G, et al: Integrating miRNA and gene expression profiling analysis revealed regulatory networks in gastrointestinal stromal tumors. Epigenomics 8: 1347-1366, 2016.

46. Dufour A, Sampson NS, Zucker S and Cao J: Role of the hemopexin domain of matrix metalloproteinases in cell migration. J Cell Physiol 217: 643-651, 2008.

47. Kuniyasu H, Ukai R, Johnston D, Troncoso P, Fidler IJ and Pettaway CA: The relative mRNA expression levels of matrix metalloproteinase to E-cadherin in prostate biopsy specimens distinguishes organ-confined from advanced prostate cancer at radical prostatectomy. Clin Cancer Res 9: 2185-2194, 2003.

48. Kim SA, Inamura K, Yamauchi M, Nishihara R, Mima K, Sukawa Y, Li T, Yasunari M, Morikawa T, Fitzgerald KC, et al: Loss of CDH1 (E-cadherin) expression is associated with infiltrative tumour growth and lymph node metastasis. Br J Cancer 114: 199-206, 2016

49. Bonilla C, Mason T, Long L, Ahaghotu C, Chen W, Zhao A, Coulibaly A, Bennett F, Aiken W, Tullock T, et al: E-cadherin polymorphisms and haplotypes influence risk for prostate cancer. Prostate 66: 546-556, 2006.

50. Ferrara N, Gerber HP and LeCouter J: The biology of VEGF and its receptors. Nat Med 9: 669-676, 2003.

51. Yip KW and Reed JC: Bcl-2 family proteins and cancer. Oncogene 27: 6398-6406, 2008.

52. Raffo AJ, Perlman H, Chen MW, Day ML, Streitman JS and Buttyan R: Overexpression of bcl-2 protects prostate cancer cells from apoptosis in vitro and confers resistance to androgen depletion in vivo. Cancer Res 55: 44338-4445, 1995.

53. Huang WC, Chan SH, Jang TH, Chang JW, Ko YC, Yen TC, Chiang SL, Chiang WF, Shieh TY, Liao CT, et al: miRNA-491-5p and GIT1 serve as modulators and biomarkers for oral squamous cell carcinoma invasion and metastasis. Cancer Res 74: 751-764, 2014.

54. Wang J, Wang Y, Sun D, Bu J, Ren F, Liu B, Zhang S, Xu Z, Pang S and Xu S: miR-455-5p promotes cell growth and invasion by targeting SOCO3 in non-small cell lung cancer. Oncotarget 8: 114956-114965, 2017. 